\title{
Sealing Ability of Three Different Materials Used as Retrograde Filling
}

\author{
Ji-Hoon Park ${ }^{1}$, Seung-Bok Kang ${ }^{2}$, Yong-Hoon Choi ${ }^{1}$, Ji-Hyun Bae ${ }^{1}$ \\ ${ }^{1}$ Department of Conservative Dentistry, Seoul National University, \\ ${ }^{2}$ Department of Conservative Dentistry, Korean Armed Forces Capital Hospital, Seongnam, Korea
}

\begin{abstract}
Purpose: To test the apical leakage prevention performance of three different materials through protein leakage procedures using bovine serum albumin (BSA) and Bradford protein reagent.

Materials and Methods: A total of 60 human single-rooted teeth were divided into 4 groups, and conventional root canal filling was done. The root was cut $3 \mathrm{~mm}$ from the apex, and a cavity was formed. Proroot MTA (MTA), Fuji II LC (GI), Fuji II LC with XP bond (GIA), and Caviton (CA) were used as experimental materials to fill the cavity in a retrograde filling manner. The extent of BSA leakage was then measured with a ultraviolet visible spectrophotometer 24,48 , and 72 hours after filling.

Result: After 24 hours, among the 15 teeth of each group, 2 in MTA, 4 in GI, 3 in GIA, and 7 in CA showed leakage. After 48 hours, 3 in MTA, 5 in GI, 5 in GIA, and 10 in CA had leakage and discoloration. After 72 hours, among the 15 teeth of each group, 3 in MTA, 6 in GI, 5 in GIA, and 10 in CA showed leakage. The leakage in the CA group was greater than that in the MTA group at 48 and 72 hours based on Fisher's exact test $(\mathrm{P}=0.025)$, and the difference was statistically significant. Similarly, the leakage in the CA group was greater than that in the MTA group over time based on the Kaplan-Meier survival estimate $(\mathrm{P}=0.011)$, and the difference was statistically significant.

Conclusion: Glass ionomer, glass ionomer after adhesive application, and MTA all showed leakage. Caviton showed greater leakage compared to MTA 48 and 72 hours after filling, and the difference was statistically significant; thus suggesting that Caviton is not appropriate as retrograde filling material considering its sealing ability.
\end{abstract}

Key Words: Caviton; Glass ionomer; Leakage; MTA; Protein leakage procedure; Retrograde filling

\section{Introduction}

Apicoectomy and tooth transplantation proce- dures are effective methods of preserving a tooth in case root canal therapy fails - despite its high success rate - for reasons such as complexity of the

\footnotetext{
Corresponding Author: Ji-Hyun Bae

Department of Conservative Dentistry, Seoul National University Bundang Hospital, 82, Gumi-ro 173 beon-gil, Bundang-gu, Seongnam 463-707, Korea

TEL : +82-31-787-2780, FAX : +82-31-787-4068, E-mail : beigeh@snubh.org

We would like to thank Seoul National University Bundang Hospital for funding this study (11-2009-014).

Received for publication October 25, 2012; Returned after revision December 3, 2012; Accepted for publication December 10, 2012

Copyright $\odot 2012$ by Korean Academy of Dental Science

(c) This is an open access article distributed under the terms of the Creative Commons Attribution Non-Commercial License (http:/ / creativecommons.org/licenses/ by-nc/3.0) which permits unrestricted non-commercial use, distribution, and reproduction in any medium, provided the original work is properly cited.
} 
root canal system, microcrack, and periodontal disease $^{1,2)}$. As a new solution that has been gaining popularity recently, teeth extracted for treatment, such as orthodontics and third molars, are excellent transplantation materials that can be used to fulfill the desire of both dentist and patient to preserve natural teeth.

Root end filling is important in procedures such as apicoectomy, tooth transplantation, and tooth replantation, and many materials including gutta-purcha, amalgam, zinc oxide eugenol, IRM (Dentsply Maillefer, Tulsa, OK, USA), super eugenol and o-ethoxybenzoic acid, composite resin, gold foil, glass ionomer, and MTA have been used. The root end filling material should have characteristics such as bioaffinity, sealing ability, and convenience of manipulation. The unwashed antigen remaining in the root canal and leaking into apical tissue necessitates root canal treatment in most cases. Thus, one of the important characteristics of root end filling material is sealing ability that prevents the egress of antigens such as bacteria and bacterial endotoxin from the root canal to the periapical tissues ${ }^{3}$.

MTA induces the appropriate healing of the apical tissue $^{4)}$ and biomineralization ${ }^{5)}$ and has many excellent characteristics as a potential root end filling material that can replace other materials. Note, however, that MTA is difficult to manipulate, and washout may occur with too much water ${ }^{6}$. Moreover, the disadvantage of long setting time of approximately 165 minutes causes problems such as leakage ${ }^{7}$, surface separation ${ }^{8,9}$, loss of continuity, and marginal adaptation ${ }^{10)}$.

Glass ionomer is one of the fillings with several merits such as good adhesive properties, fluoride release, antibacterial effect, etc ${ }^{11-13)}$.

Hydraulic temporary sealing material such as Caviton (GC Corp., Tokyo, Japan), Cavit (3M ESPE, St. Paul, MN, USA), Lumicon (Heraeus Kulzer, Tokyo, Japan), and Hy-Seal (Shofu, Kyoto, Japan), is based on calcium sulfate, hardening when it comes into contact with water inside the mouth. Chemical reactions and dentin bonding occur when the material hardens and linear hygroscopic expansion takes place, providing good sealing ability ${ }^{14)}$. Hydraulic temporary sealing materials are commonly used in dentistry. Among these, Caviton shows good sealing ability when used as temporary filling material, and it is commonly used in dental clinics. Due to its good sealing ability and convenience of manipulation ${ }^{15)}$, we wanted to know if Caviton is appropriate as retrograde filling material.

Through this study, we evaluated the sealing ability of 3 different filling materials such as MTA, glass ionomer, and Caviton to investigate possible use as retrograde filling material.

\section{Materials and Methods}

\section{Tooth Preparation}

A total of 60 single-rooted human teeth (maxillary second premolar or mandibular premolars) that had been extracted for orthodontic and periodontal purposes and within 1 month of extraction were collected and kept in phosphate-buffered saline before carrying out the experimental procedures. Contaminants on the tooth surface were removed with an ultrasonic device.

The 60 teeth were randomly divided into 4 different groups of 15 teeth each. An access cavity was formed with a round bur under constant irrigation. Radiographic images were used for working length measurement, with each canal enlarged to Protaper F3 (Dentsply Maillefer); the master apical file was \#35. Irrigation was done with $2.5 \% \mathrm{NaOCl}$ after using each instrument. \#35 gutta-purcha cone was used as master cone, with the root canal filled without sealer using the cold lateral compaction method. The root was cut at a right angle under constant irrigation using a diamond bur $3 \mathrm{~mm}$ from the root apex, and a cavity with depth of $3 \mathrm{~mm}$ was formed using a \#330 carbide bur for retrofilling. 
The cavity was washed with sterile saline and dried with paper point.

ProRoot MTA (MTA; Dentsply) was mixed following the manufacturer's instructions and used as retrofilling material. Fuji II LC (GI; GC Corp.) was packed and light-cured for $20 \mathrm{~s}$. For Fuji II LC with XP bond (GIA), a cavity was etched with Scotchbond Etchant (3M ESPE) for $15 \mathrm{~s}$, washed with water for $15 \mathrm{~s}$, and dried; XP bond (Dentsply De Trey, Konstanz, Germany) was then applied, followed by light curing for $20 \mathrm{~s}$. After filling Fuji II LC, light curing was performed for $20 \mathrm{~s}$. Caviton (CA; GC Corp.) was used as retrofilling material and packed into the cavity with wet cotton, with the excessive material removed. Two coats of nail polish were applied on each root surface except the cut root apex and crown portion to prevent leakage into the dentinal tubules. The teeth were placed in sterile saline for $24 \mathrm{~h}$ until the experimental procedure.

\section{Leakage of Bovine Serum Albumin (BSA) Protein}

A hole was formed at the bottom of a plastic bottle, and a tooth was buried with the root surface facing

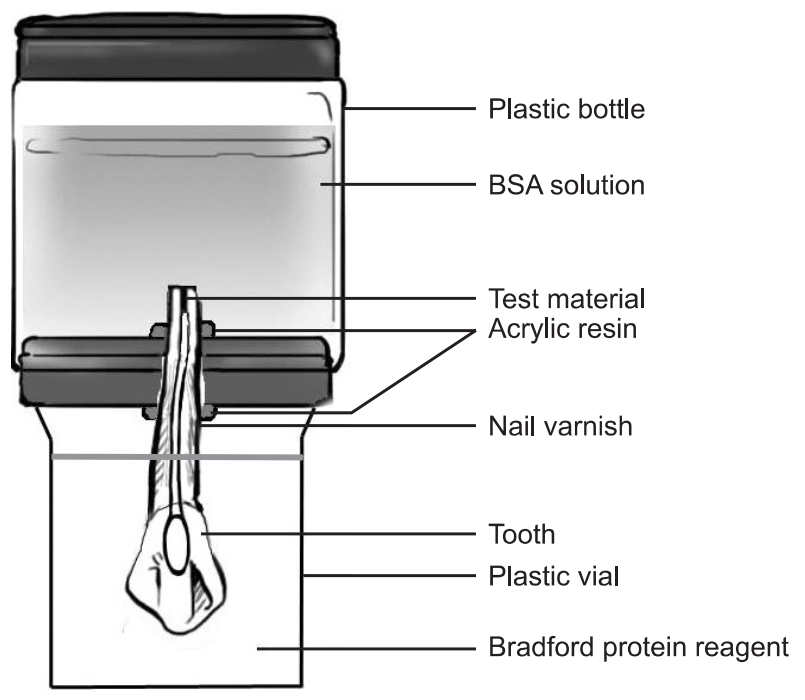

Fig. 1. Experimental device used to measure the BSA leakage procedure. BSA: bovine serum albumin. upward and subsequently fixed with acrylic resin and sealed. The root end was put inside the bottle for soaking in BSA solution, and a plastic vial filled with Bradford protein reagent was placed at the bottom of the bottle so that the crown portion could be soaked (Fig. 1) ${ }^{16)}$.

Bradford protein reagent was prepared by mixing $100 \mathrm{ml}$ of Coomasive Brilliant Blue, $50 \mathrm{ml}$ of $95 \%$ ethanol, and $100 \mathrm{ml}$ of $85 \%$ phosphoric acid; distilled water was added to make the total volume $1 \mathrm{~L}^{17)}$. A commercially produced reagent (G-250; Bio-rad Corporation, San Francisco, CA, USA) diluted to $1 / 5$ by mixing distilled water with 5 times' concentrated solution was used in this experiment. The reagent shows maximum absorbance at $595 \mathrm{~nm}$ and turns blue when it comes into contact with protein.

The optical density of the experimental group was measured using a ultraviolet visible spectrophotometer (NanoDrop ND-1000; NanoDrop Tech Inc., Rockland, DE, USA) after 24, 48, and 72 hours. The device was calibrated with distilled water, and unreacted Bradford reagent was used as background solution. The amount of protein leakage can be calculated using the Bradford assay standard curve, but only the presence of leakage was investigated in this experiment.

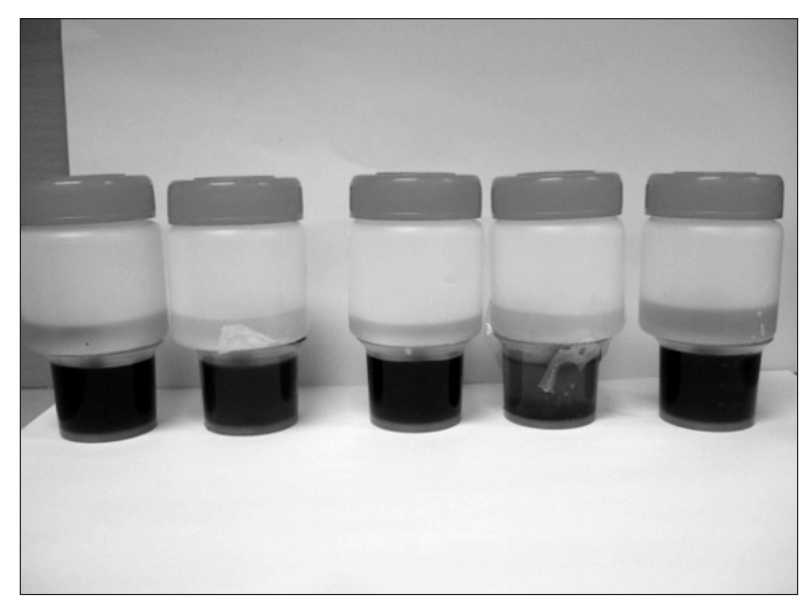

Fig. 2. The leakage caused blue discoloration of the Bradford protein reagent. 
PASW Statistics version 18.0 (IBM Corporation, Armonk, NY, USA) was used for statistical analysis. Fisher's exact test was used to analyze statistically the difference in sealing ability between materials after 24, 48, and 72 hours. The Kaplan-Meier survival estimate was used to analyze statistically the difference in leakage between materials over time. The results were considered to be statistically significant when the P-value was smaller than 0.05 .

\section{Result}

The leakage caused the blue discoloration of the Bradford protein reagent (Fig. 2).

The absorbance of the unreacted solution was around 0.1 ; protein microleak causing discoloration was deemed to have occurred if optical density was greater than 0.1 at $595 \mathrm{~nm}$ (Fig. 3) ${ }^{17}$.

The number of teeth showing leakage after 24,48 , and 72 hours is shown in Table 1 and Fig. 4.

Fisher's exact test was used to analyze statistically the difference in sealing ability between materials after 24,48 , and 72 hours, as a result of which no statistically significant difference was found among the MTA, GI, and GIA groups in terms of leakage.

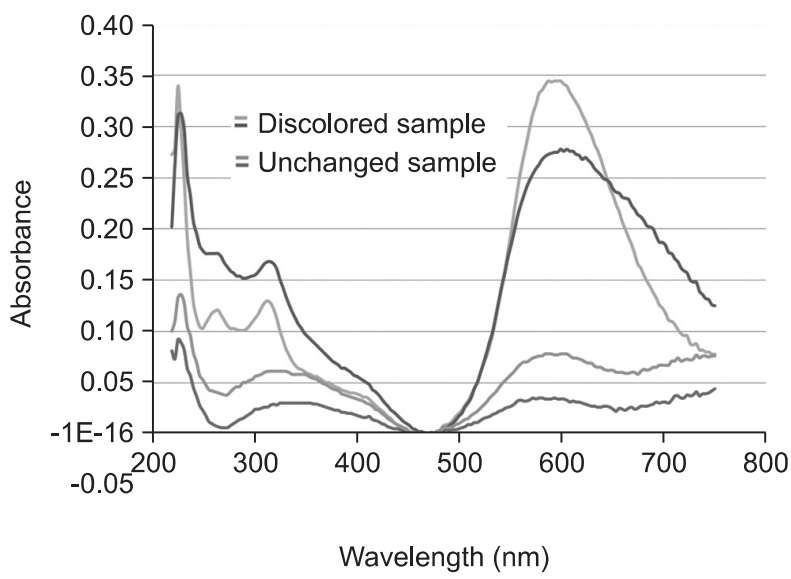

Fig. 3. Spectrophotometric graph. In the Bradford assay, protein microleak causing discoloration was deemed to have occurred if the absorbance was greater than 0.1 at $595 \mathrm{~nm}$. All samples belong to the MTA group at 24 hours. Only 2 samples discolored.
The CA group showed significantly greater leakage compared to MTA at 48 and 72 hours $(\mathrm{P}=0.025)$, however.

The Kaplan-Meier survival estimate was used to analyze statistically the difference in leakage between materials over time. The leakage in the CA group was greater than that in the MTA group $(\mathrm{P}=0.011)$, and the difference was statistically significant.

Table 1. Number of teeth showing leak after 24,48 , and 72 hours

\begin{tabular}{ccccc}
\hline & $24 \mathrm{~h}$ & $48 \mathrm{~h}$ & $72 \mathrm{~h}$ & Total \\
\hline MTA & 2 & 3 & 3 & 15 \\
GI & 4 & 5 & 6 & 15 \\
GIA & 3 & 5 & 5 & 15 \\
CA $^{a}$ & 7 & $10^{b}$ & $10^{c}$ & 15 \\
\hline
\end{tabular}

The values denote the number of samples that showed leak. ${ }^{a}$ The leak in the CA group was greater than that in the MTA group over time based on the Kaplan-Meier survival estimate $(P=0.011)$, and the difference was statistically significant, ${ }^{b}$ The leak in the CA group was greater than that in the MTA group at 48 hours based on Fisher's exact test $(P=0.025)$, and the

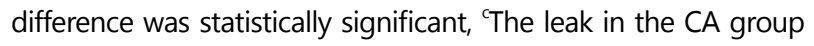
was greater than that in the MTA group at 72 hours based on Fisher's exact test $(P=0.025)$, and the difference was statistically significant.

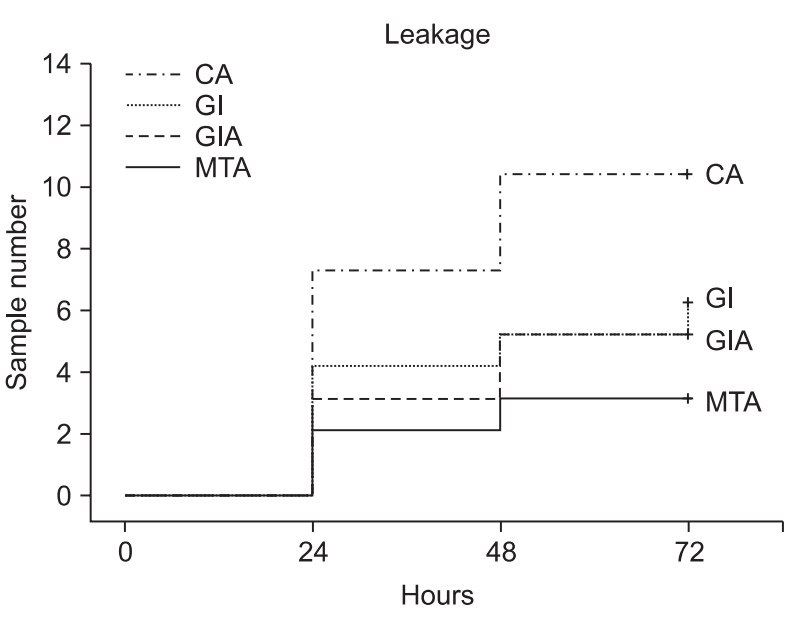

Fig. 4. The Kaplan-Meier survival estimate was used to analyze statistically the difference in leak between materials over time. The leak in the CA group was greater than that in the MTA group, and the difference was statistically significant $(P=0.011)$. 


\section{Discussion}

Among the many methods used to test the sealing ability of a material, radioisotope and dye penetration method have been commonly used. The autoradiograph (radioisotope) method traces the pathway of a radioactive material that releases radiation by conventional printing methods, and the results may be affected by factors such as the type of isotope used, distance between the radiation source and emulsion, and film exposure time. Another disadvantage is that the size of the radioisotope tracer is much smaller than bacteria, thereby resulting in a different leakage pattern ${ }^{3)}$.

The dye penetration method is the most popular method due to its simplicity, and methylene blue and India ink are generally used. In particular, methylene blue is cheap and easy to handle. The dye results are also good; hence its popularity. Note, however, that the molecular size is much smaller than bacterial toxin, and the method can draw incorrect results due to osmotic and capillary action ${ }^{18)}$. India ink is also commonly used but has problems, i.e., occurrence of dissolution during the decalcification and washing process and occasional difficulty in measuring maximum penetration depth $^{19)}$. Furthermore, factors such as $\mathrm{pH}$ and chemical reactivity are known to be likely to affect the level of penetration ${ }^{20)}$.

A leakage measurement method that is gaining popularity nowadays is the albumin protein leakage procedure. This method is based on the discoloration that takes place when protein comes into contact with Coomasive Brilliant Blue as well as on the increase in optical density at $595 \mathrm{~nm}$. The extent of leakage can be measured on every surface; another advantage is that the size of bovine albumin protein is similar to bacterial lipopolysaccharide molecule ${ }^{21}$, thereby prompting us to decide on this method for this study.

As a pre-mixed temporary filling material whose components are zinc oxide, calcium sulfate, glycol acetate, polyvinylacetate resins, polyvinyl chloride acetate, and triethanolamine ${ }^{22)}$, Caviton has the advantage of minimizing the error that may occur during the mixing process. Moreover, the gypsum component in the material absorbs water and expands when the material comes into contact with water, and hardening occurs ${ }^{14,23)}$. This characteristic helps stop the leakage of bacteria and oral fluid by tightly bonding to the cavity. Note, however, that the hygroscopic characteristic of Caviton causes the material itself to absorb water, triggering dye penetration into the material itself in addition to the border between the material and cavity and causing viscous liquid component to be pushed out of the opposite side that is in contact with water by the absorbed water ${ }^{14)}$. Previous studies showed that Caviton has better sealing ability compared to Cavit and $\mathrm{IRM}^{15}$. Other studies evaluating the change in leakage according to various external factors found that the sealing ability of Caviton is not affected by heat and loading ${ }^{24)}$. As a result of our study, however, more teeth filled with Caviton showed leakage compared to MTA.

MTA is divided into the gray type and the white type. The white MTA used in this study mainly consists of tricalcium silicate and bismuth oxide; when mixed with water, calcium hydroxide and calcium silicate hydrate are formed, changing into porous gel that is not totally crystallized. It changes from gel state into a hard structure over time ${ }^{25)}$. MTA is hydrophilic, slightly expanding when it hardens. This characteristic is known to provide its superior sealing ability.

Another study reported that $\mathrm{pH}$ affects the property of MTA. Low $\mathrm{pH}$ decreases the hardness and strength of $\mathrm{MTA}^{26-28)}$, and its compressive strength decreases when mixed with $2 \%$ lidocaine $\mathrm{HCl}$ (with $1: 100,000$ epinephrine $)^{29} \cdot \mathrm{pH}$ changes caused by in vivo inflammation will likely affect the property of MTA, wielding harmful influences on the treatment results. When MTA is exposed to low $\mathrm{pH}$ as in the case of direct contact with an apical lesion, a 
mixing calcium phosphate cement matrix should be considered to prevent direct contact with an acidic environment $t^{30}$.

The glass ionomer used in this study was Fuji II $\mathrm{LC}$, and the difference in leakage in its use was compared with that in the use of other materials in case of sole use and use with dentin bonding agent. A previous study wherein Fuji II LC was used as filling of the root apex area showed that the difference between the use of bonding agent and non-use of bonding agent was not statistically significant; the same result was found in this experiment. Moreover, compared with composite resin, the Fuji II LC group was reported to show less leakage than the Admira (VOCO, Cuxhaven, Germany) resin filling group ${ }^{31)}$.

There are many factors that affect sealing ability besides the type of material. Gilheany et al. ${ }^{32)}$ performed root resection at various degrees of angulations $\left(0^{\circ}, 30^{\circ}, 45^{\circ}\right)$, formed cavities of various depths, and tested the sealing ability of various root end filling materials by doing retrofilling. The results showed that the amount of leakage decreased significantly with greater depth of apical filling and smaller amount of bevel. Torabinejad and Chivian ${ }^{33)}$ studied the effect of thickness of the root end filling material using MTA and concluded that MTA thickness of 3 4 mm is suitable. They showed in another study that MTA $4 \mathrm{~mm}$ thick has superior sealing effect compared to the $3 \mathrm{~mm}$-thick filling ${ }^{16}$.

The results of this study show that glass ionomer, glass ionomer after adhesive application, and MTA all showed leakage. In terms of sealing ability, Caviton - which is commonly used as temporary dental filling material for its ease of use and minimal leakage - cannot be used as retrograde filling material. As a limitation of this study, the statistical model used cannot do in vivo replication; dynamic and further in depth studies considering the interaction between the root canal system and tissue surrounding the root apex are necessary.

\section{Conclusion}

Glass ionomer, glass ionomer after adhesive application, and MTA all showed leakage. Caviton showed greater leakage compared to MTA at 48 and 72 hours after filling, suggesting that Caviton is not appropriate as retrograde filling material considering its sealing ability.

\section{References}

1. Bae JH, Choi YH, Cho BH, Kim YK, Kim SG. Autotransplantation of teeth with complete root formation: a case series. J Endod. 2010; 36: 1422-6.

2.Choi $\mathrm{YH}, \mathrm{Bae} \mathrm{JH}$. Clinical evaluation of a new extraction method for intentional replantation. J Korean Acad Conserv Dent. 2011; 36: 211-8.

3. Torabinejad M, Rastegar AF, Kettering JD, Pitt Ford TR. Bacterial leakage of mineral trioxide aggregate as a root-end filling material. J Endod. 1995; 21: 109-12.

4. Tawil PZ, Trope M, Curran AE, Caplan DJ, Kirakozova A, Duggan DJ, Teixeira FB. Periapical microsurgery: an in vivo evaluation of endodontic root-end filling materials. J Endod. 2009; 35: 357-62.

5. Reyes-Carmona JF, Felippe MS, Felippe WT. Biomineralization ability and interaction of mineral trioxide aggregate and white portland cement with dentin in a phosphate-containing fluid. J Endod. 2009; 35: 731-6.

6. Kim JC, Kim MR, Ko HJ, Yang WK. Apical microleakage of MTA with 4-META/MMA \& TBB resin as a root-end filling material. J Kor Acad Cons Dent. 2009; 34: 371-6.

7. Reeh ES, Combe EC. New core and sealer materials for root canal obturation and retrofilling. J Endod. 2002; 28: 520-3.

8. Davis JL, Jeansonne BG, Davenport WD, Gardiner D. The effect of irrigation with doxycycline or citric acid on leakage and osseous wound healing. J Endod. 2003; 29: 31-5.

9. Yatsushiro JD, Baumgartner JC, Tinkle JS. Longi- 
tudinal study of the microleakage of two root-end filling materials using a fluid conductive system. J Endod. 1998; 24: 716-9.

10. Peters CI, Peters OA. Occlusal loading of EBA and MTA root-end fillings in a computer-controlled masticator: a scanning electron microscopic study. Int Endod J. 2002; 35: 22-9.

11. Barkhordar RA, Pelzner RB, Stark MM. Use of glass ionomers as retrofilling materials. Oral Surg Oral Med Oral Pathol. 1989; 67: 734-9.

12. Fraga RC, Siqueira JF Jr, de Uzeda M. In vitro evaluation of antibacterial effects of photo-cured glass ionomer liners and dentin bonding agents during setting. J Prosthet Dent. 1996; 76: 483-6.

13. Prati C, Fava F, Di Gioia D, Selighini M, Pashley DH. Antibacterial effectiveness of dentin bonding systems. Dent Mater. 1993; 9: 338-43.

14. Ogura Y, Katsuumi I. Setting properties and sealing ability of hydraulic temporary sealing materials. Dent Mater J. 2008; 27: 730-5.

15. Lee YC, Yang SF, Hwang YF, Chueh LH, Chung $\mathrm{KH}$. Microleakage of endodontic temporary restorative materials. J Endod. 1993; 19: 516-20.

16. Valois CR, Costa ED Jr. Influence of the thickness of mineral trioxide aggregate on sealing ability of root-end fillings in vitro. Oral Surg Oral Med Oral Pathol Oral Radiol Endod. 2004; 97: 108-11.

17. Bradford MM. A rapid and sensitive method for the quantitation of microgram quantities of protein utilizing the principle of protein-dye binding. Anal Biochem. 1976; 72: 248-54.

18. Hwang YC, Kang IC, Hwang IN, Oh WM. Comparison of the sealing ability of various retrograde filling materials. J Kor Acad Cons Dent. 2001; 26: 379-86.

19. Ahlberg KM, Assavanop P, Tay WM. A comparison of the apical dye penetration patterns shown by methylene blue and india ink in rootfilled teeth. Int Endod J. 1995; 28: 30-4.

20. Bae JH, Kim YK, Yoon PY, Lee MA, Cho BH. Effect of a new resin monomer on the microleakage of composite resin restorations. J Kor Acad Cons
Dent. 2007; 32: 468-74.

21. Shahi S, Rahimi S, Hasan M, Shiezadeh V, Abdolrahimi M. Sealing ability of mineral trioxide aggregate and Portland cement for furcal perforation repair: a protein leakage study. J Oral Sci. 2009; 51: 601-6.

22. Yun SM, Karanxha L, Kim HJ, Jung SH, Park SJ, Min KS. Coronal microleakage of four temporary restorative materials in Class II-type endodontic access preparations. Restor Dent Endod. 2012; 37: 29-33.

23. Suehara M, Suzuki S, Nakagawa K. Evaluation of wear and subsequent dye penetration of endodontic temporary restorative materials. Dent Mater J. 2006; 25: 199-204.

24. Cruz EV, Shigetani $Y$, Ishikawa K, Kota K, Iwaku M, Goodis HE. A laboratory study of coronal microleakage using four temporary restorative materials. Int Endod J. 2002; 35: 315-20.

25. Torabinejad M, Parirokh M. Mineral trioxide aggregate: a comprehensive literature review--part II: leakage and biocompatibility investigations. J Endod. 2010; 36: 190-202.

26. Lee YL, Lee BS, Lin FH, Yun Lin A, Lan WH, Lin CP. Effects of physiological environments on the hydration behavior of mineral trioxide aggregate. Biomaterials. 2004; 25: 787-93.

27. Namazikhah MS, Nekoofar MH, Sheykhrezae MS, Salariyeh S, Hayes SJ, Bryant ST, Mohammadi MM, Dummer PM. The effect of $\mathrm{pH}$ on surface hardness and microstructure of mineral trioxide aggregate. Int Endod J. 2008; 41: 108-16.

28. Torabinejad M, Hong CU, McDonald F, Pitt Ford TR. Physical and chemical properties of a new root-end filling material. J Endod. 1995; 21: 349-53.

29. Watts JD, Holt DM, Beeson TJ, Kirkpatrick TC, Rutledge RE. Effects of $\mathrm{pH}$ and mixing agents on the temporal setting of tooth-colored and gray mineral trioxide aggregate. J Endod. 2007; 33: 9703.

30. Saghiri MA, Lotfi M, Saghiri AM, Vosoughhosseini S, Fatemi A, Shiezadeh V, Ranjkesh B. Effect of 
$\mathrm{pH}$ on sealing ability of white mineral trioxide aggregate as a root-end filling material. J Endod. 2008; 34: 1226-9.

31. Economides N, Kokorikos I, Gogos C, Kolokouris I, Staurianos C. Comparative study of sealing ability of two root-end-filling materials with and without the use of dentin-bonding agents. J Endod. 2004; 30:35-7.
32. Gilheany PA, Figdor D, Tyas MJ. Apical dentin permeability and microleakage associated with root end resection and retrograde filling. J Endod. 1994; 20: 22-6.

33. Torabinejad M, Chivian N. Clinical applications of mineral trioxide aggregate. J Endod. 1999; 25: 197205. 